\title{
Reparação de defeitos osteocondrais de cães com implante de cultura de condrócitos homólogos e membrana biossintética de celulose: avaliação clínica, ultrassonográfica e macroscópica
}

\author{
[The repair of osteochondral defects in dogs with homologous articular chondrocytes and biosynthetic cellulose \\ membrane: clinical, ultrasound and macroscopic evaluation]
}

L.S. Iamaguti ${ }^{1}$, C.V.S. Brandão ${ }^{1}$, L.S.L.S. Mota ${ }^{2}$, M.G. Sereno ${ }^{1}$, M.F. Almeida ${ }^{1}$, C.R. Padovani ${ }^{2}$

${ }^{1}$ Faculdade de Medicina Veterinária e Zootecnia - Unesp - Campus de Botucatu - Botucatu, SP ${ }^{2}$ Instituto de Biociências de Botucatu - Unesp - Campus de Botucatu - Botucatu, SP

\begin{abstract}
RESUMO
Avaliou-se o implante de condrócitos homólogos em lesões osteocondrais, utilizando a membrana biossintética à base de celulose (MBC) como revestimento. Dez cães adultos e clinicamente sadios foram submetidos à artrotomia das articulações fêmoro-tíbio-patelares. Defeitos de quatro milímetros de diâmetro por quatro milímetros de profundidade foram induzidos na tróclea femoral de ambos os membros. A MBC foi aplicada na base e superfície das lesões. Os defeitos do membro direito foram preenchidos com condrócitos homólogos cultivados e formaram o grupo tratado (GT); e os defeitos do membro esquerdo, sem implante celular, formaram o grupo controle (GC). Os animais foram avaliados clínica e ultrassonograficamente aos 30 e 60 dias. A evolução pós-operatória dos cães foi analisada com especial interesse nos processos de reparação da lesão, por meio de macroscopia. Não houve diferença clínica e ultrassonográfica entre os grupos. Entretanto, à macroscopia, ocorreu maior prevalência de formação de tecido cicatricial esbranquiçado no GT. O tecido neoformado apresentou melhor qualidade associado ao implante homólogo de condrócitos, mas não promoveu reparação por cartilagem hialina. Palavras-chave: cão, cartilagem articular, condrócitos homólogos, ultrassonografia, macroscopia
\end{abstract}

\begin{abstract}
The aim of the study was to evaluate the repair of deep cartilaginous defects made in the femoral trochlear sulcus of dogs, using the cellulose biosynthetic membrane (CBM) as coating. Ten healthy adult dogs without locomotor disorders were used. All animals were submitted to arthrotomy of stifle joints and defects with four millimeters diameter $x$ four millimeters deep were done in the femoral trochlear sulcus of both limbs. CBM was applied in the lesion's base and surface of all limbs. In the treated group (TG), the defects of the right limb were filled with cultivated homologous chondrocytes, and in control group $(C G)$, the defects of the left limb were filled without cellular implant. The animals were evaluated by physical examination and ultrasound at 30 and 60 days. The postoperative follow up of the dogs was done by macroscopy with special interest in the healing process of the osteochondral defect. No clinical and ultrasonographic differences were observed in both groups. In the macroscopic evaluation higher prevalence of whitish scar tissue formation was noted in TG, but without statistical difference. The neoformed tissue showed slightly higher quality in TG, but without promoting repair by the hyaline cartilage.
\end{abstract}

Keywords: dog, articular cartilage, homologous chondrocytes, ultrasound, macroscopy

\section{INTRODUÇÃO}

A cartilagem articular é um tecido com vida média notável. Entretanto, trauma ou instabilidade articular podem induzir a lesões importantes. Inicialmente haverá dor, disfunção articular e efusões, progredindo para sua destruição generalizada e total deformação. Um elemento estratégico para o sucesso na reparação de defeitos na superfície articular constitui no uso de materiais biológicos com ou sem implante de células (Van der Kraan et al., 2002).

Recebido em 25 de maio de 2011

Aceito em 10 de setembro de 2012

E-mail: iamaguti_lu@hotmail.com 
Membranas biossintéticas apresentam boa aceitação pelo organismo, protegendo e auxiliando a reparação de áreas lesadas por permeabilidade seletiva, além de impedir a contaminação por micro-organismos (Aslan et al., 2004). A membrana biossintética à base de celulose (MBC) foi aplicada em trocleoplastias experimentais em cães, não interferindo na biomecânica nem no ambiente intra-articular (Iamaguti et al., 2008a). Além disso, acelerou o processo de reparação inicial da região da trocleoplastia, apresentando boa integração do tecido neoformado com a cartilagem adjacente. Contudo, como elemento isolado, não é efetiva para promover completa regeneração da cartilagem articular (Iamaguti et al., 2008b).

O implante autólogo de condrócitos cultivados foi descrito em humanos e coelhos, sendo relatada a reparação com presença de formação de cartilagem hialina na maioria dos casos (Brittberg et al., 1994). A principal desvantagem do uso de condrócitos autólogos e sua ampla aplicação prática são a baixa disponibilidade, tanto em localização quanto em quantidade, para a obtenção das células cartilaginosas para o cultivo. O implante alógeno em coelhos também tem sido feito com sucesso, com baixa resposta imunogênica (Boopalan et al., 2006; Masuoka et al., 2005; Filgueiras, 2008). Entretanto, na literatura consultada, não foram encontrados estudos de implante homólogo de condrócitos em ambiente articular em cães.

Em vista disso, objetivou-se analisar a reparação do tecido cartilaginoso em defeitos experimentais profundos com a utilização da MBC como revestimento associada ao implante de condrócitos homólogos cultivados.

\section{MATERIAL E MÉTODOS}

Os procedimentos experimentais desenvolvidos estavam de acordo com os Princípios Éticos na Experimentação Animal e foram aprovados pela Comissão de Ética no Uso de Animais, sob protocolo $n^{\circ}$ 62/2009-CEUA. Dois cães de um e cinco anos de idade, que vieram a óbito no Hospital Veterinário, por motivos não infecciosos ou neoplásicos, e sem alterações macroscópicas nas articulações, foram doadores de cartilagem hialina. A coleta foi realizada imediatamente após o óbito. Foram coletados fragmentos de cartilagem com características normais das articulações fêmoro-tíbio-patelares, coxofemorais, úmero-rádio-ulnares e escápuloumerais.

Após isolamento e expansão dos condrócitos, 10 cães sadios, sem raça definida, provenientes do Biotério Central da Instituição, três fêmeas e sete machos, na faixa etária de um a seis anos, e peso médio de $12,5 \pm 4,5 \mathrm{~kg}$, foram utilizados para $\mathrm{o}$ implante celular. Todos os animais foram submetidos ao procedimento de artrotomia de ambas as articulações fêmoro-tíbio-patelares (Iamaguti et al., 2008b), sendo realizado um defeito de quatro milímetros de diâmetro por quatro milímetros de profundidade em cada sulco troclear. No membro esquerdo, grupo controle (GC), a MBC foi aplicada na base e superfície das lesões; no membro direito, grupo tratado (GT), além da MBC, nos defeitos do membro direito foram implantados condrócitos homólogos cultivados.

Os animais foram mantidos com colar elizabetano, em jaulas individuais, para limitar sua movimentação até a cicatrização da ferida cirúrgica. A antibioticoterapia profilática foi feita utilizando-se enrofloxacina, via oral, na dose de $7 \mathrm{mg} / \mathrm{kg}$ de peso, em intervalos de 24 horas, durante sete dias. $O$ anti-inflamatório e o analgésico utilizados foram o meloxicam, a cada 24 horas, na dose de $0,1 \mathrm{mg} / \mathrm{kg}$, durante os primeiros quatro dias de pós-operatório, e a morfina, na dose de $0,1 \mathrm{mg} / \mathrm{kg}$, por via intramuscular, em intervalos de 8 horas, durante dois dias. A limpeza da ferida cirúrgica foi realizada diariamente, utilizando-se uma solução aquosa de Iodopovidine a $1 \%$. Os pontos da pele foram removidos no oitavo dia do pósoperatório. Depois do final do período de observação e recuperação funcional dos membros, os animais foram doados.

Os cães foram submetidos ao exame clínico, sempre pelo mesmo examinador, e filmados com câmera nos seguintes momentos: 24 horas após a cirurgia (M1); 30 dias após a cirurgia (M30) e 60 dias após a cirurgia (M60). A função locomotora do membro foi avaliada em escores (Tab. 1), conforme modificação da classificação proposta por Aiken et al. (1992), nos diferentes momentos. 
Tabela 1. Classificação da função locomotora dos membros posteriores

\begin{tabular}{lc}
\hline Descrição da locomoção & Escore \\
\hline Ausência de claudicação durante a locomoção & 0 \\
Claudicação discreta durante a locomoção; apoio quando em estação & 1 \\
Claudicação moderada na locomoção; apoio quando em estação & 2 \\
Claudicação evidente, elevação do membro ao correr, apoio infrequente do membro & 3 \\
quando em estação & 4 \\
Claudicação sem apoio do membro (impotência funcional) & \\
\hline
\end{tabular}

Todos os animais foram submetidos ao exame ultrassonográfico das articulações do joelho antes do procedimento cirúrgico, aos 30 (M30) e aos 60 (M60) dias do pós-operatório. Para a obtenção das imagens ultrassonográficas, os cães foram posicionados em decúbito lateral, com o membro a ser examinado voltado para cima, ao lado direito do examinador, com a região cefálica do animal paralela ao aparelho de ultrassonografia e a região pélvica próxima ao lado direito do examinador. A região do joelho foi tricotomizada, com posterior aplicação de gel acústico. Foi utilizado aparelho de ultrassonografia marca GE, modelo Logic 3, e o exame foi realizado com o transdutor linear multifrequencial na frequência de 6-10 $\mathrm{MHz}$ e documentado por impressão em vídeo printer em papel 110HD tipo II e CD.

As imagens foram obtidas em planos sagital e transversal, e avaliadas na região infrapatelar com o membro flexionado e em posição neutra. Dessa forma, os tecidos moles periarticulares, cápsula articular, membrana sinovial, retináculo do joelho, margem articular, integridade dos ligamentos cruzados e superfície do tecido ósseo foram avaliados.

Aos 60 dias do pós-operatório, foi realizada artrotomia exploratória, utilizando-se o mesmo protocolo anestésico, para avaliação macroscópica. Nessa avaliação, foram observadas a presença ou ausência da membrana de celulose na superfície articular e sua fixação, as superfícies articulares e alterações na cápsula articular. Cinco parâmetros foram avaliados: reparação dos defeitos; brilho na região dos defeitos; continuidade, representada pela integração com a cartilagem adjacente; erosão do tecido de reparação, qualificados em escores presente (+) ou ausente (-); superfície da região, que foi classificada em plana ou com depressão (desnível) (Ribeiro et al., 2004).

Arq. Bras. Med. Vet. Zootec., v.64, n.6, p.1483-1490, 2012
Para a avaliação macroscópica, foi utilizado o teste de Goodman para contrastes entre e dentro de populações binomiais (Goodman, 1964; 1965). Todas as comparações foram realizadas considerando-se 5\% de significância (Zar, 1999).

\section{RESULTADOS E DISCUSSÃO}

Todos os animais apresentaram função normal dos membros avaliados, como também relatado por Breinan et al. (1997), Breinan et al. (2001) e Iamaguti et al. (2008a). Dessa forma, a cirurgia bilateral realizada em um único ato operatório e o implante de condrócitos homólogos não proporcionaram transtornos consideráveis, sendo que os cães retornaram à função normal do membro precocemente. Apesar de Sagliyan et al. (2009) observarem discreta claudicação nos animais submetidos à artrotomia de ambos os joelhos, lesão osteocondral e coleta de osso esponjoso da porção proximal da tíbia até 15 dias do pós-operatório, nenhuma complicação foi notada durante e após o ato cirúrgico, comparável ao observado neste estudo.

O exame ultrassonográfico articular possui algumas vantagens comparado a outras modalidades de diagnóstico por imagem. Tratase de um método não invasivo, rápido, seguro, com boa aceitação pelo paciente e grande acessibilidade na prática clínica (Naredo et al., 2005; Mendieta et al., 2006), como comprovado neste estudo durante as avaliações. A necessidade de apenas uma pessoa para conter os animais, dispensando a sedação ou anestesia, evidencia a praticidade do exame, assim como mencionado por Kramer et al. (1999). Além disso, o ultrassom mostra-se útil na identificação das estruturas periarticulares e no diagnóstico de anormalidades da cartilagem articular em cães (Kramer et al., 1999), características que justificam sua utilização neste trabalho.

A ausência de alterações estruturais intraarticulares nos momentos avaliados possibilitou uma avaliação geral da articulação e demonstra 
que o procedimento cirúrgico não provocou alterações aos cães dignas de nota deste estudo, fato também validado pelas avaliações clínicas. A presença de superfície articular irregular em três animais no período pré-operatório deve estar associada com desordens decorrentes da senilidade, visto que estes representavam os cães de idade mais avançada do experimento. Isso está de acordo com as descrições de mudanças artríticas discretas observadas pelo ultrassom (Kramer et al., 1999). Entretanto, ressalta-se que, durante a realização do procedimento cirúrgico, macroscopicamente, a superfície articular apresentava-se normal.

A descrição quanto ao aumento da espessura do retináculo do joelho não foi encontrada especificamente na literatura. Contudo, esse aumento pode ser explicado pelo processo inflamatório fisiológico decorrente do procedimento cirúrgico, assim como a hiperecogenicidade do coxim gorduroso infrapatelar no M30 (Fig. 1). Apesar de Kramer et al. (1999) citarem aumento da ecogenicidade do coxim gorduroso em doenças crônicas, isso não foi observado neste trabalho, visto que os cães utilizados não apresentavam nenhuma evidência de doença crônica, e a hiperecogenicidade desapareceu em sete animais aos 60 dias de avaliação.

Segundo Naredo et al. (2005), o exame ultrassonográfico tem demonstrado acurácia e confiança na identificação de efusão do joelho, associada à dor intensa durante a locomoção e no repouso. Além disso, existe certa correlação entre sinovite, efusão e parâmetros clínicos no processo de inflamação (Mendieta et al., 2006). Dessa maneira, os sinais leves de efusão, visibilizados aos 30 e 60 dias do pós-operatório (Fig. 2), não caracterizam inflamação severa da articulação devido à ausência de dor, acúmulo intenso de líquido sinovial e visibilização da cápsula articular.

De acordo com Kramer et al. (1999), a cartilagem articular pode ser visibilizada por uma linha anecoica sobre a superfície óssea, de aproximadamente um milímetro de espessura, e as anormalidades em sua superfície podem ser bem caracterizadas. No presente trabalho, contudo, a cartilagem articular e os defeitos osteocondrais criados e cartilagem adjacente não foram visibilizados em nenhum momento, mesmo com a máxima flexão do joelho dos cães.
Esse fato pode ser explicado pela localização do defeito abaixo da patela; esta, por ser uma estrutura óssea, promove formação de sombra acústica, impossibilitando a avaliação das estruturas subjacentes (Carig, 1997).

$\mathrm{Na}$ avaliação macroscópica de ambos os grupos, o retináculo e a cápsula articular, excetuando-se o espessamento no local da incisão cirúrgica, como consequência do processo cicatricial, não apresentaram outras alterações, semelhante ao citado por Iamaguti et al. (2008a). Líquido sinovial, com características macroscópicas e quantidades normais, também foi citado por Breinan et al. (1997), Breinan et al. (2001) e Iamaguti et al. (2008a). Dessa forma, nenhum animal apresentou sinal de inflamação digno de nota decorrente do procedimento cirúrgico ou do implante de condrócitos homólogos.

Assim como Iamaguti et al. (2008a), a membrana de celulose e o fio absorvível, utilizado para sua sutura, não foram visibilizados, provavelmente devido à absorção. Breinan et al. (2001), entretanto, destacaram o deslocamento do flape periosteal, que pode ser considerado uma das complicações da sua utilização. Habilidade cirúrgica manual é necessária para essa fixação, por causa da necessidade de fios de sutura fino. Filgueiras (2008) descreveu que o flape de periósteo suturado sobre a lesão é de difícil realização em articulações de animais de pequeno porte.

A distribuição das diferentes variáveis analisadas macroscopicamente estão apresentadas nas Tabelas 2, 3, 4 e 5. A formação de tecido cicatricial esbranquiçado e brilhante, na maioria dos defeitos do GT, sugere padrão discretamente mais alto de reparação promovido pelo implante de condrócitos homólogos, apesar da ausência de continuidade entre $\mathrm{o}$ tecido neoformado e a cartilagem adjacente (Fig. 3). Resultados semelhantes também foram observados por Wakitani et al. (1989) e Funayama et al. (2008), utilizando cultura de condrócitos alógenos em coelhos associados a gel de colágeno tipo I e II, respectivamente. De acordo com a superfície do tecido formado, os cães do GC apresentaram mais irregularidades quando comparado aos do GT, seja pela presença de desnível em relação à cartilagem adjacente, ou por erosões sobre o tecido de reparação. Wakitani et al. (1989) já haviam observado formação de tecido irregular nos defeitos não tratados com implante de 
condrócitos alógenos no mesmo período de avaliação.

Embora muitos métodos tenham sido desenvolvidos para o tratamento de defeitos da cartilagem articular, uma solução satisfatória de longa duração no cão ainda não foi encontrada, e os tratamentos existentes parecem estar submetidos a problemas degenerativos (Breinan et al., 2000; Breinan et al., 2001; Sagliyan et al., 2009). O principal problema dos tratamentos é a deficiência de propriedades biomecânicas do novo tecido regenerado (Tins et al., 2005). O resultado desses trabalhos e os observados neste estudo têm falhado em obter regeneração de defeitos de cartilagem em cães. Vários métodos utilizados na reparação de defeitos articulares podem auxiliar na recuperação dos sinais clínicos, como dor e diminuição na movimentação dos joelhos, mas não podem promover a formação da cartilagem articular hialina (O’Driscoll, 1998; Sagliyan et al., 2009). A fibrocartilagem como tecido de reparação não apresenta as mesmas propriedades bioquímicas e biomecânicas da cartilagem normal. Assim, a regeneração da cartilagem articular ainda representa um desafio ortopédico importante.

Tabela 2. Distribuição, nos grupos, da presença do tecido de aspecto esbranquiçado no defeito em cães

\begin{tabular}{cccc}
\hline Grupo & Ausente & Presente & Valor de P \\
Controle & $4(40,0 \%)$ & $6(60,0 \%)$ & $\mathrm{P}>0,05$ \\
Tratado & $1(10,0 \%)$ & $9(90,0 \%)$ & $\mathrm{P}<0,05$ \\
Valor de P & $\mathrm{P}>0,05$ & $\mathrm{P}>0,05$ & \\
\hline
\end{tabular}

Tabela 3. Distribuição, nos grupos, da continuidade da superfície articular em relação ao defeito (borda) em cães

\begin{tabular}{cccc} 
Grupo & Ausente & Presente & Valor de P \\
\hline Controle & $8(80,0 \%)$ & $2(20,0 \%)$ & $\mathrm{P}<0,05$ \\
Tratado & $7(70,0 \%)$ & $3(30,0 \%)$ & $\mathrm{P}>0,05$ \\
Valor de P & $\mathrm{P}>0,05$ & $\mathrm{P}>0,05$ & \\
\hline
\end{tabular}

Tabela 4. Distribuição, nos grupos, da presença de superfície plana na região central da lesão em cães

\begin{tabular}{cccc}
\hline Grupo & Ausente & Presente & Valor de P \\
\hline Controle & $7(70,0 \%)$ & $3(30,0 \%)$ & $\mathrm{P}>0,05$ \\
Tratado & $4(40,0 \%)$ & $6(60,0 \%)$ & $\mathrm{P}>0,05$ \\
Valor de P & $\mathrm{P}>0,05$ & $\mathrm{P}>0,05$ & \\
\hline
\end{tabular}

Tabela 5. Distribuição, nos grupos, da prevalência de erosão em cães

\begin{tabular}{cccc}
\hline Grupo & Ausente & Presente & Valor de P \\
Controle & $3(30,0 \%)$ & $7(70,0 \%)$ & $\mathrm{P}>0,05$ \\
Tratado & $4(40,0 \%)$ & $6(60,0 \%)$ & $\mathrm{P}>0,05$ \\
Valor de P & $\mathrm{P}>0,05$ & $\mathrm{P}>0,05$ & \\
\hline
\end{tabular}




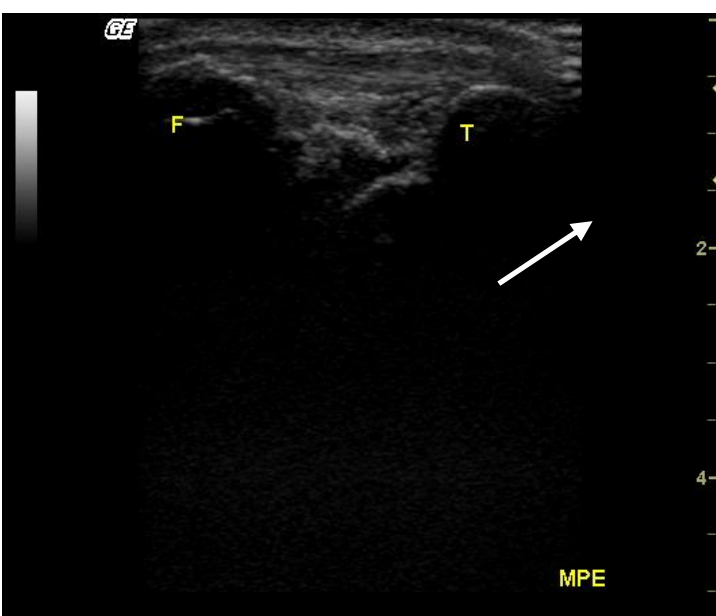

Figura 1. Cão. Imagem ultrassonográfica sagital do joelho esquerdo (GC) do animal 3 aos 30 dias. Observar a hiperecogenicidade do coxim gorduroso infrapatelar (seta).

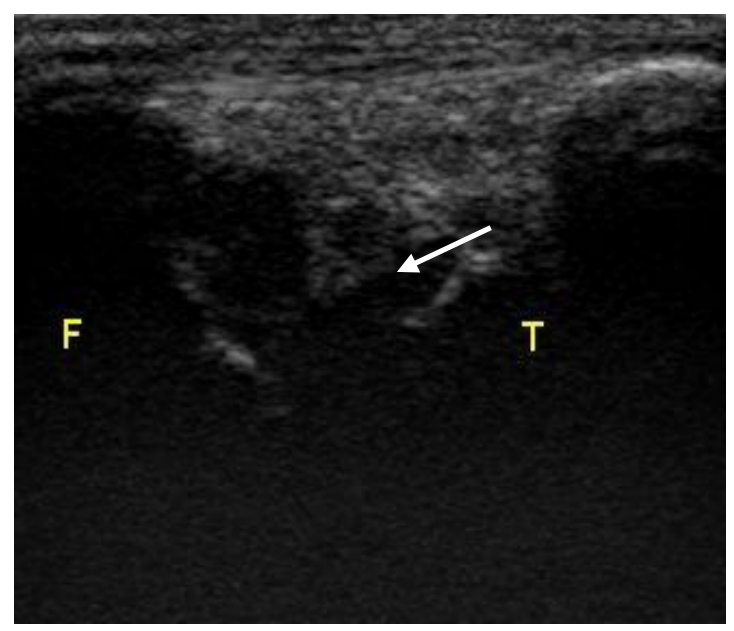

Figura 2. Cão. Imagem ultrassonográfica sagital do joelho direito (GT) do animal 4 aos 60 dias. Observar imagem anecogênica intra-articular próxima à superfície do fêmur - efusão (seta).

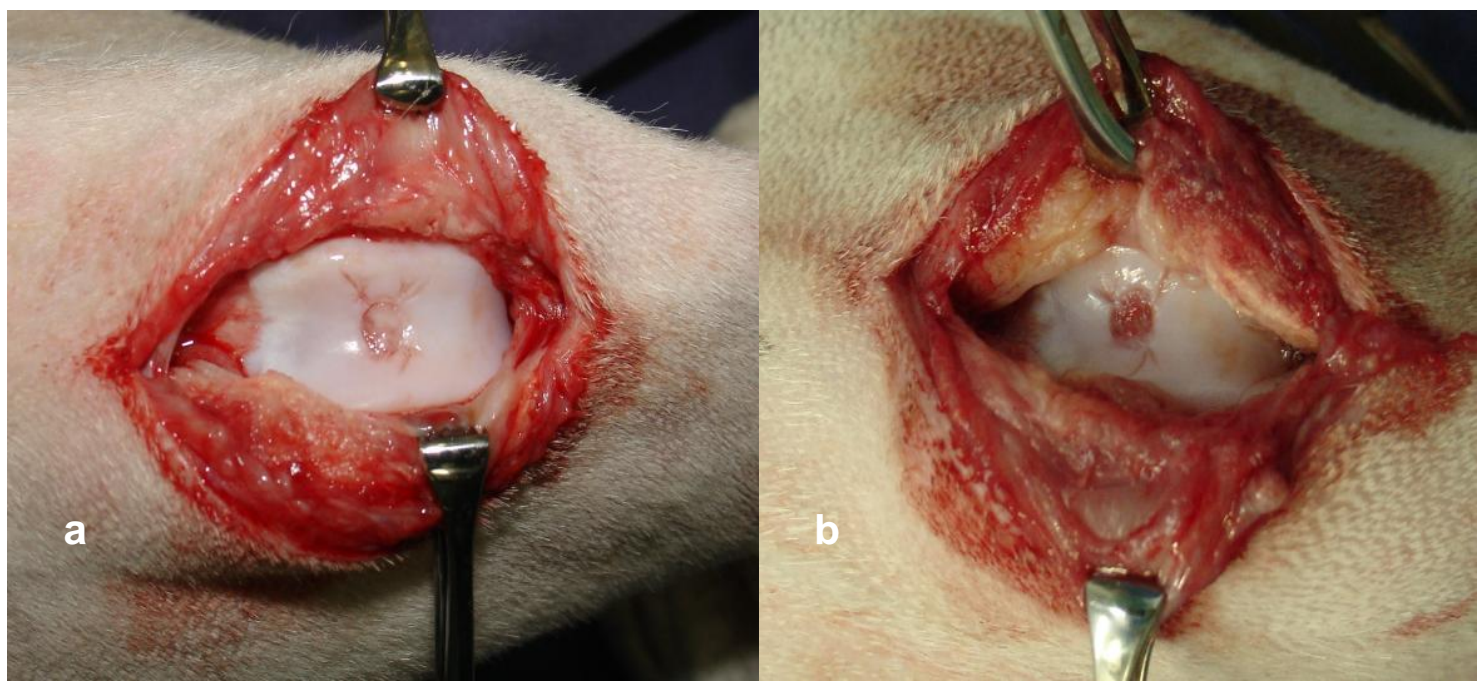

Figura 3. Cão. Região do defeito osteocondral: observar a presença de tecido de reparação de aspecto esbranquiçado em a no joelho direito (GT) do animal 6; e ausência no joelho esquerdo (GC) em b.

\section{CONCLUSÕES}

Não há diferença entre as articulações com ou sem implante de condrócitos homólogos quanto à avaliação clínica, ultrassonográfica e macroscópica. Tecido de reparação de melhor qualidade foi associado ao implante homólogo de condrócitos. Contudo, não promoveu reparação por cartilagem hialina. A membrana de biossintética de celulose apresentou boa adaptação e integração tecidual em ambiente intra-articular.

\section{AGRADECIMENTOS}

Ao CNPq pela bolsa e à Fundunesp pelo auxíliopesquisa. Ao Laboratório Ouro Fino pela doação do Maxicam $^{\circledR}$ e à Vetbrands pela doação do Enropet $^{\circledR}$. 


\section{REFERÊNCIAS}

AIKEN, S.W.; BAUER, M.S.; TOOMBS, J.P. Extra-articular fascial strip repair of the cranial cruciate deficient stifle: technique and results in seven dogs. Vet. Comp. Orthop. Traumatol., v.5, p.145-50, 1992.

ASLAN, M.; SIMSEK, G.; DAYL, E. Guided bone regeneration (GBR) on healing bone defects: a histological study in rabbits. $J$. Contemp. Dent. Pract., v.2, p.114-123, 2004.

BOOPALAN, P.R.J.V.C.; SATHISHKUMAR, S.; KUMAR, S. et al. Rabbit articular cartilage defects treated by allogenic chondrocyte transplantation. Int. Orthop., v.30, p.357-361, 2006.

BREINAN, H.A.; MINAS, T.; HSU, H.P. et al. Effect of cultured autologous chondrocytes on repair of chondral defects in a canine model. $J$. Bone Jt. Surg., v.79-A, p.1439-1451, 1997.

BREINAN, H.A.; MARTIN, S.D.; HSU, H.P. et al. Healing of canine articular cartilage defects treated with microfracture, a type-II collagen matrix, or cultured autologous chondrocytes. $J$. Orthop. Res., v.18, p.781-789, 2000.

BREINAN H.A.; MINAS T.; HSU H.P. et al. Autologous chondrocyte implantation in a canine model: change in composition of reparative tissue with time. J. Orthop. Res., v.19, p.482492, 2001.

BRITTBERG, M.; LINDAHL, A.; NILSSON, A. et al. Treatment of deep cartilage defects in the knee with autologous chondrocytes transplantation. N. Engl. J. Med., v.331, p.889985, 1994.

CARIG, C.B. Diagnostic of osteoarthritis. Vet. Clin. N. Am.: Small Anim. Clin., v.27, p.777-813, 1997.

FILGUEIRAS, R.R. Uso de condrócitos heterólogos cultivados na reparação de falhas osteocondrais produzidas no joelho de coelhos. 2008. 68p. Tese (Doutorado em Medicina Veterinária) Universidade Federal de Viçosa, Viçosa, MG.

FUNAYAMA, A.; NIKI, Y.; MATSUMOTO, H. et al. Repair of full-thickness articular cartilage defects using injectable type II collagen gel embedded with cultured chondrocytes in a rabbit model. J. Orthop. Sci., v.13, p.225-232, 2008.
GOODMAN, L.A. Simultaneous confidence intervals for contrasts among multinomial populations. Ann. Math. Statist., v.35, p.716-725, 1964.

GOODMAN, L.A. An simultaneous confidence intervals for multinomial propositions. Technometrics., v.7, p.247-254, 1965.

IAMAGUTI, L.S.; BRANDÃO, C.V.S.; MINTO, B.W. et al. Utilização de membrana biossintética de celulose na trocleoplastia experimental em cães. Avaliações clínica, radiográfica e macroscópica. Vet. Zootec., v.15, p.160-168, 2008a.

IAMAGUTI, L.S.; BRANDÃO, C.V.S.; PELLIZZON, C.H. et al. Análise histológica e morfométrica do uso de membrana biossintética de celulose em trocleoplastia experimental de cães. Pesq. Vet. Bras., v.28, p.195-200, 2008 b.

KRAMER, M.; STENGEL, H.; GERWING, M. et al. Sonography of the canine stifle. Vet. Radiol. \& Ultrasound, v.40, p.282-293, 1999.

MASUOKA, K.; ASAZUMA, T.; ISHIHARA, M. et al. Tissue engineering of articular cartilage using an allograft of cultured chondrocytes in a membrane-sealed atelocollagen honey-shaped scaffold (ACHMS Scaffold). J. Biom. Mater. Res. Part B: Applied Biomat., v.75B, p.177-184, 2005.

MENDIETA, E.M.; IBÁÑES, T.C.; JAEGER, J.U. et al. Clinical and ultrasonographic findings related to knee pain in osteoarthritis. Osteoarth. Cartil., v.14, p.540-544, 2006.

NAREDO, E.; CABERO, F.; PALOP, M.J. et al. Ultrasonographic findings in knee osteoarthritis: A comparative study with clinical and radiographic assessment. Osteoarth. Cartil., v.13, p.568-574, 2005.

O'DRISCOLL, S.W. The healing and regeneration of articular cartilage. J. Bone Jt. Surg., v.80A, p.1795-1812, 1998.

RIBEIRO, J.L.; CAMANHO, G.L.; TAKITA, L.C. Estudo macroscópico e histológico de reparos osteocondrais biologicamente aceitáveis. Acta ortop. Bras., v.12, p.16-21, 2004.

SAGLIYAN, A.; KARABULUT, E.; UNSALDI, E. et al. Evaluation of the activity of intraarticular hyaluronic acid in the repair of experimentally induced osteochondral defects of the stifle joint in dogs. Vet. Med., v.54, p.33-40, 2009. 
TINS, B.J.; McCALL, I.W.; TAKAHASHI, T. et al. Autologous chondrocyte implantation in knee joint: MR imaging and histologic features at 1-year follow-up. Radiol., v.234, p.501-508, 2005.

VAN DER KRAAN, P.M.; BUMA, P.; VAN KUPPEVET, $\mathrm{T}$. et al. Interaction of chondrocytes, extracellular matrix and growth factors: relevance for articular cartilage tissue engineering. Osteoart. Cart., v.10, p.631-637, 2002.
WAKITANI, S.; KIMURA, T.; HIROOKA, A. et al. Repair or rabbit articular surfaces with allograft chondrocytes imbedded in collagen gel. J. Bone Jt. Surg., v.71A, p.74-80, 1989.

WAKITANI, S.; GOTO, R.; YOUNG, R.G. et al. Repair of large full-thickness articular cartilage defects with allograft articular chondrocytes embedded in a collagen gel. Tiss. Eng., v.4, p.429-444, 1998.

ZAR, J.H. Biostatistical analysis. 4th ed. Hal. New Jersey:Prentice, 1999, 663p. 